\title{
Estratégias operatórias frente ao trabalho repetitivo
}

\author{
Juliana Machion Gonçalves ${ }^{\mathrm{a} *}$, João Alberto Camarotto ${ }^{\mathrm{b}}$ \\ a*jumachion@dep.ufscar.br, UFSCar, Brasil \\ bcamarotto@dep.ufscar.br, UFSCar, Brasil
}

\begin{abstract}
Resumo
Nas últimas décadas tem ocorrido a consolidação do sistema produtivo local de joias folheadas e bijuterias no município de Limeira, SP, gerando inúmeros postos de trabalho, empregos e desenvolvimento econômico do município.Na fabricação de joias é predominante a utilização do trabalho manual, caracterizado como trabalho repetitivo, ligado principalmente aos processos de montagem e soldagem. Este trabalho analisou a atividade de soldadoras das indústrias de joias folheadas, adotando, como abordagem teórico-metodológica, os pressupostos da Ergonomia Situada, a fim de compreender as estratégias operatórias adotadas frente ao trabalho repetitivo. 0 estudo verificou a percepção por parte das soldadoras de que as exigências físicas prevalecem na atividade de trabalho, mas que elas agem sobre a organização, tendo um trabalho coletivo e flexibilidade para alterar modos operatórios, regulando o seu trabalho. Devido à experiência, trabalho coletivo, pausas e possibilidades de aceleração ou diminuição do ritmo de trabalho, as soldadoras conseguem manter-se trabalhando frente ao trabalho repetitivo.
\end{abstract}

\section{Palavras-chave}

Trabalho repetitivo. Ergonomia situada. Joias folheadas.

\section{Introdução}

0 município de Limeira, SP, observa o crescimento e a consolidação do seu sistema produtivo local em fabricação e montagem de joias folheadas e bijuterias (Suzigan et al, 2003). É predominante a utilização de trabalhos manuais, observando-se os seguintes processos: montagem, soldagem e a galvanoplastia com a folheação. Segundo Vilela \& Ferreira (2008), há diversas doenças ocupacionais relacionadas com montagem ou soldagem nos processos manufatureiros da indústria de joias e bijuterias.

Estudo de Alves et al. (2002) em uma fábrica de joias mostra que, além de repetitivas, as tarefas realizadas requerem habilidade e destreza manual, movimentos firmes e precisos. A exigência de responsabilidade e atenção pode conduzir a um aumento da contração muscular estática, a qual pode contribuir para a sobrecarga muscular global. Os resultados obtidos mostram que o trabalho, apesar de repetitivo, não é essencialmente físico. Ele também exige concentração, atenção e responsabilidade.
Todas essas exigências determinam as posturas, principalmente as estáticas. Para os autores, as tarefas são realizadas sob pressão temporal e em um contexto onde o erro não é permitido, pelas consequências possíveis (perda de matéria-prima). A pressão temporal e o medo de errar podem aumentar a atividade muscular.

Surge um questionamento a partir dessa descrição: Como é a saúde desses trabalhadores frente ao trabalho repetitivo? Como é o trabalho real em função das exigências presentes no trabalho repetitivo?

Há uma relação entre saúde e trabalho. Em primeiro lugar, porque ao conseguir os resultados desejados, os trabalhadores reafirmam a sua autoestima, desenvolvem as suas habilidades, expressam as suas emoções, como descrito no estudo de Assunção \& Luz (2001). Em segundo lugar, o trabalho é uma via para desenvolver a personalidade. Relacionar-se com o outro por meio do material a ser transformado, torna possível constituir os coletivos de trabalho e assim os trabalhadores, aos 
poucos, constroem sua história e sua identidade social. Em suma, para Assunção (2003), os trabalhadores constroem a saúde através da mobilização consciente ou não das potencialidades de adaptação do ser humano, que permitem-lhe interagir com o meio de trabalho, lutando contra as doenças.

Segundo Lima (1998), a saúde ocorre graças à ampliação do espaço de regulação de sua carga de trabalho. Portanto, uma das hipóteses é que a saúde no trabalho ocorre na regulação individual que o indivíduo faz durante a atividade.

Com o intuito de apreender a diversidade de uma situação de trabalho, a ergonomia propõe uma metodologia própria de intervenção - a análise da atividade com os pressupostos da Análise Ergonômica do Trabalho (Guérin et al., 2001).

A partir do ponto de vista da atividade, os aspectos da situação do trabalho podem ser conhecidos e investigados da maneira como realmente acontecem, permitindo ao ergonomista intervir nas situações de trabalho e contribuir para a manutenção da saúde dos trabalhadores. Esse conhecimento permite também corroborar o desenvolvimento das competências e, ao mesmo tempo, garantir os objetivos econômicos determinados pela empresa (Guérin et al., 2001). Segundo Abrahão \& Pinho (2002), urge, pois, desenvolver pesquisas que compreendam o trabalhador inserido nos diversos contextos de trabalho, seja eles complexos, criativos, repetitivos ou monótonos.

Para Assunção \& Lima (2002), todo trabalho que solicita movimentos repetitivos só se realiza graças à capacidade dos trabalhadores de desenvolverem representações, modos operatórios, resolverem problemas, antecipá-los e tomar decisões durante a sua execução. Além disso, a autora refere que os gestos podem ser repetitivos, mas o trabalho tem sua variabilidade, mesmo quando são estreitas as margens para regular a carga de trabalho. Em um trabalho puramente manual, o operador deve estar atento para garantir os objetivos da produção. 0 trabalho é considerado repetitivo a partir da análise da atividade em uma situação real com todo o seu contexto organizacional. Portanto, apesar de a literatura descrever que há queixas em relação ao trabalho repetitivo, a manutenção da saúde pode ocorrer em função da margem de liberdade existente para desenvolvimento de estratégias, modos operatórios, resolução de problemas e tomada de decisões. Estudar o trabalhador nesse contexto possibilita compreender o trabalho na sua totalidade, na interação de seus componentes: instrumentos, artefatos, organização do trabalho, materiais e competência dos trabalhadores.
Portanto, esta pesquisa teve como objetivo compreender as estratégias operatórias adotadas pelos trabalhadores frente ao trabalho repetitivo para a manutenção da saúde, no setor de soldagem nas indústrias de joias folheadas e bijuterias na cidade de Limeira. Este estudo compreendeu também a verificação, do ponto de vista dos trabalhadores, da identificação das formas de regulação do modo operatório, a diferença entre trabalho prescrito e real e a verificação dos aspectos determinantes da atividade.

\section{Métodos da pesquisa}

0 estudo utiliza uma pesquisa baseada em Estudo de caso. Esse tipo de método se enquadra como uma abordagem qualitativa e é frequentemente utilizado para coleta de dados na área de estudos organizacionais, sociais, políticos e de grupo, além de na de outros fenômenos relacionados (Yin, 2005). Trata-se de uma análise aprofundada de um ou mais objetos (casos), para permitir o seu amplo e detalhado conhecimento (Gil, 1996; Berto \& Nakano, 1998).

A abordagem teórico-metodológica realizada foi a Ergonomia Situada, em que se aplica a Análise Ergonômica do Trabalho (AET). Suchman (1987, apud Leplat, 2004) refere que a Ergonomia Situada ou Ação Situada tem o papel de realizar observações sobre a ampliação do cenário da tarefa durante a atividade, evidenciando a importância do contexto em que está inserido o trabalho.

Nas primeiras visitas à empresa, de observação aberta e conhecimento do funcionamento da organização, ocorreu questionamento de se as soldadoras desenvolviam trabalho repetitivo, uma vez que não apresentavam nenhuma DORT ou queixas aparentes. Diante de uma soldadora com 18 anos de empresa, surgiu a seguinte questão: Como uma pessoa pode submeter-se a trabalho repetitivo e não apresentar queixas? 0 que as soldadoras fazem para manterem-se trabalhando, mesmo com queixas? A partir disso foi realizada uma pesquisa bibliográfica sobre essas questões.

A demanda foi reformulada juntamente com a direção da empresa e com as soldadoras no sentido de realizar uma análise do trabalho de forma situada no setor de solda, a fim de detectar os aspectos determinantes da atividade que fazem com que as soldadoras se mantenham trabalhando, apesar de apresentarem queixas.

A partir disso surgiu uma questão de pesquisa: Como essas operadoras regulam suas atividades de modo a manter a saúde no trabalho, considerando que 
a literatura aponta esse trabalho como potencializador de acometimento de LER-DORT? Além disso, mesmo que solicite movimentos repetitivos, a saúde no trabalho é possível graças à capacidade de as soldadoras desenvolverem representações, modos operatórios, resolverem problemas, antecipá-los e tomarem decisões durante o trabalho real. Ao se analisar o trabalho repetitivo, deve-se analisar a atividade em uma situação de trabalho em todo o seu contexto organizacional. Assim ter-se-á a possibilidade de detectar a manutenção da saúde, mesmo que a literatura descreva que podem desenvolver queixas em relação ao trabalho repetitivo.

De posse dessas primeiras observações, foram formuladas hipóteses para explicar a demanda. As observações abertas foram realizadas verificando-se o funcionamento da empresa e as características dos trabalhadores através da análise de documentos e entrevistas. Foram verificados aspectos relacionados à data de fundação da empresa, descrição ambiental, horário de trabalho, divisão de setores da empresa, processos de produção, sazonalidade, pagamento por produtividade, conhecimento de todas as tarefas da empresa etc.

$\mathrm{Na}$ análise das tarefas foram observados e descritos aspectos do espaço de trabalho, da produção das soldadoras e da tarefa de preparar o amianto e de soldar. Juntamente foi realizada a análise da atividade. Para comprovar ou refutar a hipótese, foram realizadas observações sistemáticas da atividade das trabalhadoras do setor de solda, totalizando 200 horas de observação, em diferentes dias do mês e da semana, por um período de 10 meses. A atividade foi observada durante um intervalo de tempo, para quantificar ações e operações, foram feitas perguntas como "o que", "como" e "por que", para compreender os determinantes da atividade, e foi observada a atividade sem a intervenção do ergonomista, para a compreensão dos aspectos subjetivos existentes nessa situação de trabalho. As categorias observáveis foram as comunicações, as posturas, ações e tomada de decisões e em relação à dimensão coletiva e ao sistema técnico. A partir disso foram acompanhandos todos os gestos, a diferença prescrito-real, as variáveis e as estratégias capazes de modificar o trabalho.

Foi feito o registro das verbalizações espontâneas dos trabalhadores durante as observações e, em casos específicos, foram feitas entrevistas simultaneamente à realização das tarefas, com o objetivo de esclarecer eventuais dúvidas sobre a atividade de trabalho. Foram utilizados lápis e papel para anotações e máquina fotográfica para registro da atividade das soldadoras nos postos de trabalho. Foram coletados dados de como os trabalhadores percebem e representam esse trabalho, resolvem problemas e organizam-se para responder ao sistema através de entrevistas semiestruturadas. Para a análise dos dados das entrevistas, foram feitas transcrições, identificando temas, dimensões, categorias, tendências e relações existentes para realizar a interpretação e a descrição. Foram selecionadas palavras-chave nas entrevistas para ilustrar a ideia e as respostas dos participantes. 0 pesquisador se comprometeu a apresentar uma resposta para a empresa com a análise dos resultados encontrados.

Nesse contexto, a observação da situação real de trabalho, o registro das verbalizações e a realização das entrevistas com os sujeitos foram indispensáveis para a análise da atividade. A validação, com o trabalhador, dos dados colhidos na análise foi importante para a explicitação das informações não observáveis da atividade, que se referem às representações. Foram realizados dois tipos de validações: do tipo autoconfrontação, no momento de realização da atividade, e em grupo, na qual foram mostrados os resultados da análise e realizadas discussões com todas as oito soldadoras sobre a situação de trabalho. Esse tipo de validação foi pouco eficiente, pois foi realizada em dois dias, com tempo de 15 minutos em cada dia. Foram apresentados material impresso, vídeos e fotos para as soldadoras, que puderam explicitar os comentários desejados sobre 0 material, colocados na descrição da atividade realizada nessa pesquisa. Encarregado e diretor não estavam presentes nessa validação. Por fim, chegou-se a um diagnóstico, baseado nos fatores identificados no processo de análise, demanda, funcionamento da empresa, interpretação de dados da análise sistemática e explicitações fornecidas pelos operadores.

Portanto, a partir do ponto de vista da atividade, os aspectos da situação do trabalho podem ser conhecidos e investigados da maneira como realmente acontecem, permitindo ao ergonomista entender o trabalho real. Esse conhecimento permite o desenvolvimento das competências e, ao mesmo tempo, garante os objetivos econômicos determinados pela empresa (Guérin et al., 2001).

\section{A situação de trabalho estudada}

A população estudada é de mulheres denominadas soldadoras. Nesse setor há sete trabalhadoras na tarefa de soldar e uma para preparar amianto, sendo todas mulheres. Quando necessário, há duas trabalhadoras da solda que ficam na preparação. A idade delas varia de 20 a 43 anos, o tempo de empresa, de um mês a 18 
anos. A empresa funciona das $7 \mathrm{~h}$ às $17 \mathrm{~h}$, de segunda a quinta-feira, e das $7 \mathrm{~h}$ às $16 \mathrm{~h}$ de sexta-feira, com uma hora de almoço (das $11 \mathrm{~h}$ às $12 \mathrm{~h}$ ).

Há um salário fixo para produzir o mínimo de peças por dia, como mostra o Tabela 1, mas não foi dito qual seria esse salário fixo. 0 encarregado refere que o salário fixo é correspondente a produzir esse número de peças no dia, de acordo com o pedido dos clientes. Há 10 anos que o salário é o mesmo. Entretanto há um prêmio por produtividade. Foi realizado um estudo durante um ano para verificar qual seria o número mínimo de peças a serem produzidas e qual o valor a ser pago por prêmio de produtividade. Cada bolinha tem um tempo de solda. Segundo o encarregado, por exemplo: A bolinha 7 tem produção diária de 1.150 peças e a bolinha 13 , de 650 peças. No caso das peças de estamparia (todas as peças que não são bolinhas), a produtividade/dia é de 1.150 peças. Além disso, há alguns trabalhos de solda fria que são realizados segundo a demanda dos clientes, para os quais a meta de produtividade é de 850 peças/dia.

Em um determinado dia de observação, a trabalhadora tinha de produzir as bolinhas 7 e 13 . 0 cálculo funciona da seguinte maneira: somam-se os dois valores $(1.150+650)$, dando 1.700 . Verifica-se a média (divide-se por dois), o que dá o mínimo de 850 peças por dia, de cada uma das peças. Se uma das trabalhadoras fez 1.150 peças totais (das duas bolinhas) e era para fazer 850 , ela vai receber $\mathrm{R} \$$ 0,0083 por peça que fez a mais, ou seja, vai receber esse valor em relação a 300 peças.

A meta de produção é controlada pelo encarregado há 15 anos, não havendo mudança até os dias de hoje. Se entrar uma trabalhadora nova, ela não consegue fazer essa produção mínima. Ele dá três meses para ela produzir a quantidade mínima. A novata tem dificuldades de manusear o maçarico na

Tabela 1. Relação entre diâmetro da bolinha e produtividade/dia.

\begin{tabular}{cc}
\hline Diâmetro da bolinha & Produtividade/dia (peças) \\
\hline 2,5 & 1350 \\
3,0 & 1300 \\
4,0 & 1250 \\
5,0 & 1200 \\
6,0 & 1175 \\
7,0 & 1150 \\
8,0 & 1100 \\
9,0 & 1050 \\
10 & 900 \\
11 & 850 \\
13 & 650 \\
15 & 450 \\
Bolinha Marina & 2200 \\
\hline
\end{tabular}

mão esquerda, pelo cuidado que se precisa ter para não colocar a tocha do maçarico próximo ao próprio corpo ou próximo às peças, para não derretê-las. Além disso, ela precisará aprender a manusear a pinça na mão direita, com movimentos de preensão e flexão de punho, coordenados com o maçarico, para realizar a soldagem. Portanto, ela só consegue atingir a quantidade mínima de peças por volta desses três meses. Mas, para não comprometer a produção, normalmente contratam soldadoras com experiência de outra fábrica de joias. Para diferenciar as novatas das experientes surgiu esse prêmio de produtividade. Hoje em dia, todas atingem a produção e ganham o salário fixo. Um jeito para diferenciar quem produz mais é manter esse prêmio.

Uma pessoa novata que entra na empresa e é treinada pelo operador mais experiente. Pode mostrar um conceito de produção artesanal. Normalmente, a pessoa já tem que ter experiência com solda. A experiente vai supervisionando o serviço do novato. Na cidade, não existe nenhum curso de solda. Segundo o encarregado, o sindicato queria assumir esse treinamento, mas como o sindicato de joias se localiza em São Paulo, a distância impediu esse curso. Ele refere também que a habilidade de solda com bolinha não é todo mundo que aprende, dependendo das características da pessoa. Segundo ele, solda é prática e aproximadamente três meses é o suficiente para aprender.

0 trabalho é individual, mas elas dividem as peças entre elas, para que todas possam ganhar a mais em relação a essa produtividade. Há uma cooperação desse coletivo de trabalho, para que todas possam ter um salário fixo e manter um salário extra. Isso acontece da seguinte forma: chega um pedido para a soldagem e elas dividem esse pedido, de modo que haja serviço "bom" para todas elas. Serviço bom é aquele em que a realização da solda, rende em produção e tem tempo de ciclo inferior a 10 segundos. É o caso de esferas denominadas "bolinhas Marina", esferas com diâmetro inferior a $7 \mathrm{~mm}$ e colocação de pino em peças de estamparia. Entretanto, há também os serviços "ruins", nos quais as soldadoras têm ciclo acima de 10 segundos, casos de soldar argolas, correntes, solda fria etc. A representação das soldadoras em relação ao seu trabalho relaciona produtividade, ciclo de trabalho e trabalho coletivo.

Há dois tipos de tarefas no setor de solda. A primeira é preparar o amianto e a segunda soldar as peças. Ao preparar amianto, joga-se o recipiente em cima do amianto, um tabuleiro de posicionamento de esferas e outras peças. Esse amianto é um material refratário, não deixa passar calor, é antifogo, não deixa deformar a peça e é um material leve. Há dois tipos de amianto: uns que são cheios de buracos e outros 
que são lisos. Quando o amianto é cheio de buracos é utilizado para posicionar as esferas e quando são lisos, para posicionar as peças de estamparia. As peças de estamparia são placas de latão utilizadas para fazer brincos e pingentes. As esferas são utilizadas para fazer brincos, pingentes e pulseiras. Após terem colocado as esferas no amianto, pegam uma pinça e posicionam a esfera em cada furo do amianto, com a "frente" voltada para cima. A esfera tem uma "frente" que apresenta um furo e uns espaços, por onde escorre a solda para fixarem-se os acessórios necessários, como pinos. Ao terminar o amianto, é posicionado no armário para que as soldadoras nos armários para que as soldadoras as peguem para realizar sua tarefa. Observam atentamente a esfera, de modo que não esteja amassada e que os furos estejam preservados. Uma observação vista no trabalho é o modo como regulam seu modo operatório, de forma que selecionam a quantidade certa para colocar as esferas no amianto. Memorizam e ficam atentas para ver o quanto é necessário de esferas em cada amianto.

Ficam na posição sentada e fazem movimentos de punho em flexão. 0 ciclo de montagem completa do amianto varia de $5 \mathrm{~min}$ a $6 \mathrm{~min}$, para colocar de 100 a 200 esferas no amianto. Levam em média dois segundos para colocar cada esfera no amianto. Há variação no tamanho do amianto e nas peças a serem colocadas. Quando é estamparia, podem colocar as peças no amianto ou não. Mas, com a esfera, é necessário colocar no amianto. $\mathrm{Na}$ estamparia, as próprias soldadoras colocam no amianto liso. Como existe somente uma pessoa para preparar amianto, elas se auto-organizam de modo que sempre há na produção revezamento na soldagem de peças de estamparia e esferas. Quando as esferas são menores, de 3,4 ou $5 \mathrm{~mm}$, pegam o recipiente e jogam no amianto e as esferas já se posicionam nos buracos do amianto. Os buracos são grandes, o que facilita o posicionamento das esferas. Elas mexem o amianto e as esferas já se acomodam.

“[...] dou uma chacoalhada nas bolinhas... ganho tempo nas bolinhas menores..."

Elas olham, prestam atenção e inspecionam para ver se as esferas estão "viradas para a frente". Senão, pegam a pinça e posicionam a esfera, para que ela fique virada para cima. Apesar de as esferas serem confeccionadas na empresa, elas apresentam irregularidades na forma, tendo uma variedade de aberturas das esferas. Ao prepararem o amianto, quando a esfera tem seu furo muito aberto, elas utilizam uma pinça para fechá-la. É uma maneira de resolver o problema e aproveitar a esfera. lsso não está prescrito. Além disso, inspecionam defeitos das peças na hora em que põem as esferas no amianto.
Se não detectam os defeitos - as soldadoras podem ou não detectar, sendo a inspeção de qualidade nesse processo -

"[...] as peças ficam abertas... fecho elas com uma pinça.... dou uma ajeitadinha na peça..."

Há uma estratégia de usar o próprio tempo de forma a integra-lo com o tempo das soldadoras para descansar e trabalhar. Fazem pausas e aceleram o trabalho para conseguir organizar seu ritmo e tempo de forma adequada. Organizam seu ritmo de trabalho de acordo com o trabalho das outras soldadoras. Entretanto, não pode haver atraso na preparação do amianto. Precisam adequar seu ritmo de trabalho para preparar o amianto em coordenação com as sete soldadoras.

[....] tem que posicionar direitinho para elas... senão elas perdem tempo...

[...] se fizer muito depressa acabam os amiantos e fico sem serviço... se elas estão adiantadas, tenho que por muito... se estão atrasadas, vou mais devagar... não posso atrasar de jeito nenhum..."

Conversam com as colegas junto ao trabalho ou param em alguns momentos do ciclo para conversar com as colegas sobre assuntos não ligados ao trabalho. É um modo de coordenar seu trabalho e utilizar seu tempo de acordo com a necessidade das soldadoras. Elas autoaceleram ou vão devagar à medida que as soldadoras estão realizando sua tarefa. Estão acostumadas a ter seu ritmo de trabalho, suas pausas, e quanto mais peças colocam, maior será seu prêmio por produtividade.

“[...] vou devagar porque já fiz bastante... se eu atraso, as meninas esperam e não pode... não pode perder tempo..."

Quando é a esfera chamada "Bolinha Marina" a ser produzida, começam a preparar o amianto com antecedência, pois é mais rápido soldar do que preparar. É antecipação da trabalhadora para realizar a preparação e não comprometer a produção. Se as soldadoras já tiverem terminado o trabalho, pegam outra peça para soldar até que tenham todo o amianto preparado para soldar a esfera.

“[...] quando é Marina, não dão conta de preparar enquanto a gente solda... soldar é rapidinho... é mais rápido soldar do que preparar..."

A segunda tarefa a ser realizada é a soldagem. Pegam o pino/gancho/argola com a pinça na mão direita, põem um pouco de solda (cortada em microquadrados) no pino, passam o maçarico, que está na mão esquerda. 0 maçarico esquenta a solda e gruda o pino no espaço da "frente" da esfera. A solda escorre nos riscos. Para cada esfera há um 
tipo de solda e tipo de pino. Foi verificado que é importante ter precisão e atenção ao desenvolver esse trabalho. Desenvolver habilidade para utilizar essas ferramentas dessa maneira ao realizar a tarefa de soldar. Cada uma deve ter na memória qual o tipo de solda a ser utilizado, senão elas se comunicam entre si e verificam o tipo de solda necessária para a esfera. As mais experientes sabem de memória qual tipo de solda deve ser usada na esfera a ser produzida. Às vezes, a soldadora experiente sabe até o tipo de solda, mas confirma com a mais experiente, gerando essa interação entre elas. Para a esfera de $9 \mathrm{~mm}$ precisa do pino 80 e solda 11 .

“[...] não tem problema... depois põe o pino 80... (pino de 8/10 de espessura e 11 de comprimento) [...] você tá com qual solda. ... to com a 11 ...”

Há diversos tipos de esferas e a bola maior tem que ser esquentada, exposta por maior tempo ao maçarico. Desse modo, aumenta o tempo de ciclo em comparação ao das esferas menores. Além disso, seguram a pinça com pressão por maior tempo, mantendo o punho em postura estática.

\section{“[...] é ruim soldar bola maior... tem que esquentar muito..."}

Quanto menor a esfera, menos tempo deixam o maçarico para esquentá-la e fazer escorrer a solda. Se a esfera está com seu buraco muito aberto, precisam colocar mais solda nesse local. Dependendo de como está posicionada a esfera, a soldadora tem de virá-la com a frente para cima para colocar a solda no buraco da esfera. Quanto mais “soldarão”, mais rápido a solda escorre pelos espaços.

Em relação ao ciclo de trabalho, é influenciado pelo diâmetro da esfera, pelo tamanho do buraco da esfera, pelo posicionamento da esfera no amianto, pela quantidade de "soldarão" em volta da esfera. 0 "soldarão" é um produto químico utilizado juntamente com água para realizar a fervura da esfera. Cada esfera tem um tipo de solda. A partir da esfera $13 \mathrm{e}$ 15 colocam duas soldas, porque uma não é suficiente para fechá-las. Esse tipo de esfera tem tempo de ciclo de colocar pino nela de aproximadamente 17 segundos. Entretanto, a esfera 11 tem um tempo de ciclo que varia de 14 a 16 seg. 0 Tabela 2 mostra a observação sistemática realizada na empresa, verificando-se os tempos de ciclo de cada tamanho de esfera.

0 ciclo total de preenchimento do amianto varia em torno de 30 minutos. Ao produzir a "Bolinha Marina", pegam um fio de solda com a pinça na mão direita e, com a mão esquerda, o maçarico. Ao derreter a ponta do fio de solda, colocam-na em cima da esfera, com movimentos circulares, de modo que a solda escorra nos espaços da esfera. Há uma coordenação no trabalho, de modo que podem dividir
Tabela 2. Relação do tipo de esfera com tempo de ciclo de soldagem por peça.

\begin{tabular}{cc}
\hline Diâmetro da esfera & Tempo de ciclo (segs) \\
\hline 2,5 & 6 \\
3,0 & 6 \\
4,0 & 7 \\
5,0 & 8 \\
6,0 & 8 \\
7,0 & 10 \\
8,0 & 10 \\
9,0 & 10 \\
10 & 13 \\
11 & 14 \\
13 & 17 \\
15 & 17 \\
Marina & 3 \\
\hline
\end{tabular}

entre elas a produção para não faltar peças para nenhuma delas. Quando pegam o amianto, escolhem o que tem mais peças, assim não levantam tanto e ganham prêmio maior por produção. Segundo elas, é vantagem, pois a produção de Marina é um "serviço bom”, que apresenta ciclo inferior a cinco segundos e leva ao aumento de produtividade.

“[...] quando faz Marina é porque o pedido é grande, porque normalmente vai para rua..."

Em média são 120 peças em cada amianto, e demoram 10 minutos para terminar um amianto, sendo que o ciclo varia de dois a quatro segundos. Dividem a produção de Marina:

\section{"[...] é seis amiantos para cada uma..."}

Depois que terminam a produção de Marina, pegam as esferas de uma caixa e com as mãos fazem a inspeção visual para ver se uma esfera grudou na outra. A soldadora experiente reconhece a esfera grudada pelo barulho. Mexe na caixa e passa maçarico nelas para desgrudar as esferas. A trabalhadora mais novata prefere por de uma em uma esfera na caixa, para ver se grudaram.

\section{“...] tá vendo esse barulho fininho... tá grudada..."}

A trabalhadora novata solda aleatoriamente enquanto que a experiente solda em uma ordem. Ela tem a medida exata no maçarico, enquanto a novata fica com o maçarico mais tempo na peça. A novata não olha para o brinco, se as peças ficaram tortas ou não, diferentemente da experiente, que olha após o termino da solda. Ela não conversa com as outras e senta-se em uma mesa sozinha. Diferentemente das outras, que se sentam em duplas.

“[...] fico quieta... sou nova... preciso ver direito o que faço..." 
Uma estratégia adotada pela trabalhadora para evitar esforços nos punhos e soltar as peças mais rapidamente é colocar peças de estamparia em uma latinha com tampa, chacoalhar e retirar as peças, jogando-as em uma peneira. Retiram o excesso de "soldarão" ao colocar na peneira e põem em uma caixinha. Isso faz com que as peças se soltem e a trabalhadora não faça esforço ao desgrudar as peças. Não têm que utilizar seu tempo para desgrudar peça por peça. Desgrudam tudo de uma vez só.

\section{"[...] tá vendo... fica fácil... solta todas as peças..."}

Uma questão importante a ser levantada são as pausas realizadas durante a jornada de trabalho. A importância da pausa está ligada ao tempo de recuperação muscular e alternância de posturas, para minimizar os efeitos do trabalho repetitivo presente na tarefa de preparar amianto e soldar. A maioria delas realiza pausas em um tempo de até cinco minutos. Além dessa pausa relatada pelas soldadoras, há a pausa inserida na atividade, onde a cada amianto preparado ou a cada soldagem de esferas do amianto completo (média de 30 minutos), saem de seu posto de trabalho, alternando a postura sentada para em pé e vão pegar novo amianto no armário, deslocando-se uns três metros.

\section{Considerações finais sobre o trabalho da soldadora}

No trabalho de soldagem de joias folheadas e bijuterias foi verificado que há um processo de regulação individual e em grupo, onde as soldadoras agem sobre a organização, têm um trabalho coletivo e flexibilidade para alterar modo operatório, regulando o seu trabalho. 0 saber específico, desenvolvido pelas soldadoras, permitiu que elas ajustassem o modo operatório aos seus recursos cognitivos e fisiológicos, favorecendo a construção da saúde. A relação entre trabalho repetitivo e possibilidade de planejamento da atividade gerou liberdade, dada às soldadoras pela organização do trabalho, contribuindo para a saúde e evitando a ocorrência de LER/DORT.

0 foco desta pesquisa foi verificar e caracterizar o trabalho repetitivo e o trabalho de precisão do ponto de vista da atividade, num contexto real de trabalho, verificando as interações e movimentos para explicar a regulação do trabalho. A pesquisa considerou a relação dinâmica entre o indivíduo que trabalha e a situação de trabalho.

0 trabalho das soldadoras foi caracterizado como de ciclos inferiores a 30 segundos, de acordo com a visão biomecânica/cinesiológica relatada por Silverstein et al. (1986). Para Lima (1998), o tempo não é determinado de uma forma tão simples, já que há variabilidades presentes na situação de trabalho e uma atividade de trabalho bem dinâmica. A variabilidade esteve presente, principalmente ligada às peças. Em relação ao ciclo de trabalho, ele variou de dois a 20 segundos, aproximadamente. lsso aconteceu em função do diâmetro da esfera (de $2,5 \mathrm{~mm}$ a $24 \mathrm{~mm}$ ), do tamanho do buraco da "frente" da esfera, do posicionamento da esfera no amianto (com a "frente" para cima), da quantidade de "soldarão" em volta da esfera (produto químico utilizado juntamente com água para realizar a fervura da esfera). Desse modo, há uma relação com o que Coutarel et al. (2005) descrevem, pois em situações fortemente repetitivas, com ciclos curtos, existe uma variabilidade da matéria-prima, do tipo de demanda, do estado do maquinário etc. que leva o trabalhador a mudar o seu modo operatório, exigindo, portanto, planejamento da ação.

As soldadoras realizam movimentos repetitivos na soldagem e preparação de amianto, com ciclos curtos, mas também desenvolvem representações, modos operatórios, antecipação, resolução de problemas e tomada de decisões durante a execução do trabalho. Como refere Wisner (2004), a cada momento que se armazenam informações pela ação (na atividade) e para a ação (buscando um objetivo) vão se construindo representações e criando competências. É por meio das representações que o indivíduo seleciona informações relevantes e procedimentos mais assertivos para realizar uma tarefa. A cada situação de trabalho, o indivíduo cria competências diferenciadas para a ação.

Para Assunção (2003), mesmo em situações rígidas, as pessoas executando tarefas semelhantes não trabalham da mesma maneira em função das suas características individuais. Sob esse ponto de vista, a saúde seria resultado de uma "negociação" entre os objetivos da produção e o estado interno dos trabalhadores.

0 trabalho objeto dessa pesquisa, além de repetitivo, guarda um caráter exclusivo de precisão, sendo manual. Para Lima \& Silva (2002), a atividade manual é importante devido à riqueza do comportamento, caracterizado por flexibilidade, adaptabilidade, desenvolvimento e aperfeiçoamento das formas de regulação. A tarefa manual de precisão, no caso das soldadoras, requer habilidade e destreza manual e a objetivação do saber prático, com um caráter de exclusividade, pois não há como eliminar o trabalho humano na soldagem de joias. A interpretação do sentido e significado dos imprevistos, a experiência e a tomada de decisão em tempo real contribuíram para a regulação no trabalho e adoção de estratégias operatórias. 0 saber específico da atividade teve a função de permitir às soldadoras ajustarem o modo operatório aos seus recursos cognitivos e fisiológicos, contribuindo para a construção da saúde. 
Para Colombini et al. (2008), a carência de períodos de recuperação pode levar a sobrecarga biomecânica por movimentos e/ou esforços repetitivos em membros superiores. Para Maciel (2000), deve haver um tempo de recuperação com pausas suficientes. Para a autora, os efeitos dos movimentos repetitivos são mais acentuados quando são realizados com aplicação de forças. No caso das soldadoras, não há aplicação de força, mas existem períodos de recuperação muscular, pois realizam micropausas quando desempenham tarefas de inspeção de peças, pausas a cada 30 minutos, quando trocam o amianto, e pausas para ir ao banheiro, tomar café, entre outras. Essas pausas são formas de regulação, para evitar que haja o adoecimento da soldadora.

Segundo Kuorinka \& Forcier (1995), as queixas correspondem a acúmulo de carga ultrapassando a capacidade de adaptação de um tecido, surgindo como sinal de alerta. As situações que potencialmente apresentam uma degradação da atividade de trabalho, levam a um fator de risco, havendo diminuição da capacidade para o trabalho. Apesar de as soldadoras trabalharem com dor, ainda não houve a diminuição para a capacidade no trabalho, em função dessa forma de regulação instalada nesse coletivo, através das pausas.

0 estudo de Alves et al. (2002) em uma fábrica de joias mostra que, além de repetitivas, as tarefas realizadas requerem habilidade e destreza manual, movimentos firmes e precisos. Há exigência de responsabilidade, concentração e atenção no desenrolar das atividades que determinam as posturas.

A soldadora inspeciona defeitos das peças e retira os pelotes de solda. Esse é o momento em que ela alterna a postura de punhos e mãos, regulando o trabalho, pois desenvolve uma atividade diferente de soldar. Ao preparar o amianto, a experiência contida na memória, a atenção às irregularidades na forma e abertura das esferas, o aproveitamento das esferas foram exemplos de atividade que alterna com as tarefas manuais, criando outro espaço de regulação onde não utiliza como postura a preensão e movimentos de pinça. Quando a operadora que prepara amianto coloca as esferas nele, inicia pela parte superior, deixando um espaço na parte inferior, no qual pode pegar as esferas restantes (que sobram em cima do amianto) e jogar na caixa, não tendo que retirar as esferas em excesso uma a uma com a pinça. Consegue, com isso, usar seus movimentos de punho somente para por as esferas e não para retirar o excesso. É uma nova forma de regulação.

Nas peças de estamparia, uma estratégia adotada pelas soldadoras para evitarem esforços em punhos e soltarem as peças mais rapidamente foi colocarem as peças em uma latinha com tampa, chacoalharem e retirarem as peças, jogando-as em uma peneira. As peças soltavam-se e elas não faziam esforço ao desgrudá-las. Nem tiveram de utilizar seu tempo para desgrudarem peça por peça. Desgrudam tudo de uma vez só, sendo outra forma de regulação do trabalho.

Com as esferas menores, de 3 , 4 ou $5 \mathrm{~mm}$, pegam o recipiente, jogam no amianto e as esferas já se posicionam nos buracos do amianto. Os buracos são grandes, o que facilita o posicionamento das esferas. Elas mexem o amianto e as esferas já se acomodam, regulando o trabalho e não tendo que usar movimentos de pinça e preensão para colocarem as esferas no amianto.

Na peça chamada capacete, a soldadora precisa estar atenta, pois necessita soldar dois acessórios muito parecidos e precisa memorizar e aplicar na peça. Usam a estratégia de deixar um acessório no seu lado esquerdo e o outro do lado direito, próximo a sua área de alcance. As experientes já conseguem diferenciar os acessórios, posicionando próximo um do outro.

A operadora que prepara amianto adotou uma estratégia de usar seu tempo de forma a integra-lo ao tempo das soldadoras, para descansar e trabalhar. Faz pausas e acelera o trabalho para organizar seu ritmo e tempo de forma adequada, regulando o seu trabalho. Organiza seu ritmo de trabalho de acordo com o trabalho das soldadoras.

Na produção da "Bolinha Marina", começam a preparar o amianto com antecedência, pois é mais rápido soldar do que preparar. Essa antecipação na realização da preparação do amianto visa não comprometer a produção. Se as soldadoras terminam o trabalho, podem pegar outra peça para soldar, já que todo o amianto está preparado para soldar a "Bolinha Marina".

Segundo Oliveira \& Jacques (2006), as evidências apontam a relação entre trabalho repetitivo, tarefas fragmentadas e executadas sob pressão, pouca possibilidade de defender e planejar a prescrição das tarefas, submissão a controles organizacionais rígidos e a ocorrência de LER/DORT.

Para Assunção (2003), os trabalhadores constroem a saúde através da mobilização consciente ou não das potencialidades de adaptação do ser humano, o que lhes permite interagir com o meio de trabalho e lutar contra as doenças. Segundo Lima (1998), a saúde ocorre graças à ampliação do espaço de regulação de sua carga de trabalho. 0 adoecimento no trabalho ocorre em função da sobrecarga no estado interno do operador, onde não há liberdade para modificar os objetivos, meios e regular seu trabalho.

As soldadoras tiveram liberdade, aumentando esse espaço de regulação, conseguindo a manutenção 
da saúde, mesmo com queixas. Foi percebido que não houve sobrecarga em seu estado interno, e que obtiveram flexibilidade em seu modo operatório. Para Assunção (2003), as estratégias dos indivíduos construídas com a experiência no trabalho podem servir de argumento para alargar as margens da organização do trabalho. Desse modo, a implementação dessas estratégias e a elaboração de outras podem compensar o declínio da atividade e evitar o surgimento de fatores de risco para a saúde daqueles que ainda não adoeceram, apesar de encontrarem-se sobrecarregados.

Dejours (2000) refere que uma tarefa repetitiva pode gerar sentimentos contraditórios ao pensamento. Quando não há a aceleração do trabalho, há margem de pensamento criativo para criar representações mentais, emocionais e afetivas, evitando-se a monotonia do trabalho. 0 trabalho da soldadora não foi caracterizado como monótono. 0 conceito de monotonia e repetitividade apresentam uma relação importante, pois ao realizarem a atividade, as soldadoras aumentaram o ciclo de trabalho através dos trabalhos "bom" e "ruim", deixando grande margem de pensamento criativo para criar representações, resolver problemas e tomar decisões.

Carayon (2000) descreve que em uma organização baseada no trabalho em equipe há níveis altos de participação, o que gera ambiente psicossocial positivo de trabalho. Além disso, se houver determinadas pausas, pode reduzir-se a exposição a cargas físicas, o que ocorre no trabalho da soldadora.

Segundo Dejours (2000), à medida que o pensamento se retira, o corpo torna-se mais frágil e, no caso de sobrecarga, os sintomas se expressam de forma somática. lsso ocorre no trabalho repetitivo sob constrangimento de tempo, onde a sintomatologia se orienta para o corpo e não para a mente. No caso das soldadoras há esse tipo de constrangimento em função do prêmio por produtividade. 0 que faz com que haja aceleração do ritmo de trabalho, podendo-se intensificar o próprio trabalho de forma planejada, o que gera custo e desgaste para a soldadora. Desse modo, surgem as queixas, pois elas aumentam o ritmo e há modo operatório acelerado que pode levar a sobrecarga de trabalho.

Para Carayon (2000), exigências de cotas de produção podem levar a pressão e tensão entre os integrantes da equipe. Há nesse trabalho uma meta de produção para as soldadoras, controlada pelo encarregado. Se uma trabalhadora novata inicia seu trabalho nessa empresa, não consegue fazer essa produção mínima incialmente, pois tem dificuldades para manusear o maçarico com a mão esquerda, pelo cuidado que se precisa ter para não colocar a tocha do maçarico próxima do próprio corpo ou próxima às peças, para não derretê-las. Além disso, precisa aprender a manusear a pinça com a mão direita, com movimentos de preensão e flexão de punho coordenados com o maçarico para realizar a soldagem. Elas só conseguem atingir a quantidade mínima de peças por volta dos três meses. Mas para não comprometer a produção, normalmente contratam-se soldadoras com experiência de outra fábrica de joias. A pessoa novata que entra na empresa é treinada pelo operador mais experiente. lsso mostrou um conceito de produção artesanal. Normalmente, a pessoa já tem que ter experiência com solda. A experiente sempre irá supervisionar o serviço do novato.

Segundo as soldadoras, o trabalho de soldagem é estimulado pelo prêmio por produtividade, favorecendo o aumento de adicional no salário. Não referiram nada negativo como esforço físico para alcançar a meta. É um dilema existente nesta pesquisa, pois a regulação no trabalho é para favorecer a saúde, mas as soldadoras ganham por produção, intensificando o trabalho.

A hipótese dos trabalhos de Laville (1989) é que a compensação das queixas, como fruto da experiência, permite aos indivíduos confrontados às situações reais de trabalho atingirem as metas de produção mesmo em situações degradadas. Com a experiência, os operadores adaptam cada vez mais suas estratégias em função do seu custo físico, em termos de esforços a empreender e do tempo destinado à realização das tarefas. Trata-se de um saber específico do trabalhador sobre as suas próprias competências num campo particular ou numa situação dada (Assunção, 2003).

As relações afetivas também interferem na construção do coletivo de trabalho. 0 trabalho foi caracterizado como individual, mas as soldadoras dividiam as peças entre elas, para que todas pudessem ganhar a mais em relação a essa produtividade, sendo essa uma forma de regulação que intensificou o trabalho. Entretanto, a cooperação desse coletivo de trabalho criou uma forma de regulação, alternando ciclos de trabalho. Um ciclo de dois segundos ao produzir "Bolinhas Marina” é pior que um ciclo de 17 segundos para produzir esferas 15. Houve a divisão de pedidos, com serviços "bons" e "ruins" para todas. Serviço bom é aquela solda que rende em produção e tempo de ciclo inferior a 10 segundos. Foi o caso de "Bolinhas Marina", esferas com diâmetro inferior a $7 \mathrm{~mm}$ e colocação de pino em peças de estamparia. Entretanto, existem também os serviços "ruins", com ciclo acima de 10 segundos, caso de soldar argolas, correntes, solda fria etc. A representação das soldadoras em relação ao seu trabalho referiu produtividade, ciclo de trabalho e trabalho coletivo. 
Como mostra o estudo de Assunção (2003), também entre as soldadoras uma das regras do coletivo é não deixar o colega em uma situação difícil, ou seja, numa situação em que os seus meios e as suas capacidades são frágeis para responder às exigências das tarefas.

Finalizando, foi possivel verificar que novos estudos são necessários para entender todas as etapas do processo de fabricação de joias, com a realização de Análise Ergonômica do Trabalho. Este trabalho foi produzido em um tipo de empresa. É importante analisar diferentes produtos e diferentes tamanhos de empresas, como também empresas verticalizadas e horizontalizadas, para entender o contexto global das empresas de joias. Seria necessário também realizar estudos estatísticos em empresas verticalizadas e horizontalizadas, já que os dados colhidos junto ao INSS tiveram pouca relevância.

\section{Referências}

Abrahão, J. 1., \& Pinho, D. L. M. (2002). As transformações do trabalho e desafios teórico-metodológicos da Ergonomia. Estudos de Psicologia, 7(n. Especial), 45-52. http://dx.doi.org/10.1590/S1413-294X2002000300006

Alves, G. B. 0., Assunção, A. A., \& Luz, M. G. (2002). Abordagem Ergonômica no estudo das posturas do trabalho: 0 Caso de uma Fábrica de Joias. Revista de Terapia Ocupacional da Universidade de São Paulo, 13(3), 111-117. http://dx.doi.org/10.11606/issn.22386149.v13i3p 111-117

Assunção, A. A., \& Luz, M. G. (2001). 0 componente afetivo na atividade da enfermagem: o caso do banco de leite humano. Revista Mineira de Enfermagem, 5(1), 13-19.

Assunção, A. A., \& Lima, F. P. A. (2003). A contribuição da ergonomia para a identificação, redução e eliminação da nocividade do trabalho. In R. Mendes (Org.), Patologia do trabalho (2. ed. rev. ampl., Vol. 2, pp. 1767-1789). São Paulo: Atheneu.

Assunção, A. A. (2003). 0 saber prático construído pela experiência compensa as deficiências físicas provocadas pelas condições inadequadas de trabalho. Revista Trabalho e Educação, 12(1), 35-49.

Berto, R. M. V. S., \& Nakano, D. N. (1998). Métodos de Pesquisa na Engenharia de Produção. In XVIIl Encontro Nacional de Engenharia de Produção, Niterói. Retrieved from http://www.abepro.org.br/biblioteca/enegep 1998 art174.pdf

Carayon, P. (2000). A organização do trabalho e os DORTs no setor de serviços. In L. 1. Swnelwar \& L. Nadim (Org.), $O$ trabalho humano com sistemas informatizados no setor de serviços (pp. 21-35). São Paulo: Pleiade.

Colombini, D., Occhipinti, E., \& Fanti, M. (2008). Método OCRA para a análise e a prevenção do risco por movimentos repetitivos: manual para a avaliação e a gestão do risco. São Paulo: LTr.

Coutarel, F., Daniellou, F., \& Dugué, B. (2005). La prévention des troubles musculo-squelettiques: quelques enjeux épistémologiques. Activités, 2(1). Retrieved from http:// www.activites.org/v2n1/coutarel.pdf

Dejours, C. (2000). Novas formas de organização do trabalho e LER: Abordagem através da Psicodinâmica do Trabalho. In L. 1. Swnelwar \& L. Nadim (Org.), O trabalho humano com sistemas informatizados no setor de serviços (pp. 38-40). São Paulo: Pleiade.

Gil, A. C. (1996). Como Elaborar Projetos de Pesquisa. São Paulo: Atlas.

Guérin, F., Laville, A., Danielou, F., Durafourg, J., \& Kerguelen, A. (2001). Compreender o trabalho para transformá-lo: a prática da ergonomia. São Paulo: Edgar Blücher.

Kuorinka, 1., \& Forcier, L. (Org.) (1995). LATR: les lésions attribuables au travail répétitif: ouvrage de référence sur les lésions musculo-squelettiques liées au travail. Canadá: Multi Mondes.

Laville, A. (1989). Vieillissement et travail. Le travail humain, 52(1), 3-19.

Leplat, J. (2004). Aspectos da complexidade em ergonomia. In F. Daniellou (Coord.), A ergonomia em busca de seus princípios: debates epistemológicos (pp. 57-78). São Paulo: Edgard Blücher.

Lima, F. P. A. (1998). L.E.R - Dimensões Ergonômicas e Psicossociais. In J. N. G. Araújo, F. P. A. Lima \& M. E. A. Lima (Orgs.), Ergonomia e prevenção da LER: possibilidades e limites. Belo Horizonte: Editora Health.

Lima, F. P. A., \& Silva, C. A. D. (2002). A objetivação do saber prático na concepção de sistemas especialistas: das regras formais às situações de ação. In F. Duarte (Org.), Ergonomia e Projeto na indústria de processo contínuo (pp. 84-121). Rio de Janeiro: COPPE/RJ.

Maciel, R. H. (2000). Prevenção da LER/DORT: o que a ergonomia pode oferecer. In Brasil, Cadernos de saúde do Trabalhador. Retrieved from http://www.coshnetwork. org/sites/default/files/caderno9\%20ler-dort.pdf

Oliveira, S., \& Jacques, M. G. C. (2006). Políticas e práticas de gestão e saúde: recortes sobre o trabalho de teleatendimento no Rio Grande do Sul. Revista Brasileira de Saúde Ocupacional, 31(114), 63-72. http://dx.doi. org/10.1590/S0303-76572006000200006

Silverstein, B. A., Fine, L. J., \& Armstrong, T. J. (1986) Hand wrist cumulative trauma disorders in industry. British Journal of Industrial Medicine, 43(11), 779784. Retrieved from http://www.ncbi.nlm.nih.gov/pmc/ articles/PMC1007752/pdf/brjindmed00175-0059.pdf

Suzigan, W., Garcia, R., Furtado, J., \& Sampaio, S. E. K. (2003). Sistemas Locais de Produção: mapeamento, tipologia e sugestões de políticas. In Encontro Nacional de Economia, Porto Seguro.

Vilela, R. A. G. \& Ferreira, M. A. L. (2008). Nem tudo brilha na produção de joias de Limeira - SP. Produção, 18(1), 183-194. http://dx.doi.org/10.1590/S010365132008000100014

Wisner, A. (2004). Questões epistemológicas em Ergonomia e Análise do Trabalho. In F. Daniellou (Coord.), A ergonomia em busca de seus princípios: debates epistemológicos (pp. 29-55). São Paulo: Edgard Blücher.

Yin, R. K. (2005). Estudo de Caso: Planejamentos e Métodos. Porto Alegre: Bookman. 


\title{
Operational strategies adopted in the repetitive work
}

\begin{abstract}
In the past decades, we have seen the consolidation of the local productive system of plated jewelry in the municipality of Limeira, Sao Paulo state. This market has created many jobs and work opportunities contributing to the city's economic development. In jewelry manufacturing, there is predominance of manual work, characterized as repetitive work, mainly associated with the processes of assembly and welding. This study analyzed the activity of plated jewelry female welders using a theoretical-methodological approach and the precepts of located ergonomics in order to understand the operational strategies adopted against the repetitive work. The study verified the welders' perception that the physical demands prevail in work activities, but they work on the organization, collective work, and flexibility to change the operating mode, adjusting it to their work. Because of their experience and expertise, collective work, breaks, and the possibility of accelerating or decreasing the pace of work, the welders have been able to keep performing the repetitive work.
\end{abstract}

Keywords

Repetitive work. Located ergonomics. Plated jewelry. 